\title{
LRG1 promotes angiogenesis through upregulating the TGF- $\beta 1$ pathway in ischemic rat brain
}

\author{
HONGMEI MENG ${ }^{1}$, YUEJIA SONG ${ }^{2}$, JIYUAN ZHU ${ }^{1}$, QI LIU ${ }^{1}$, PENGTIAN LU ${ }^{1}$, \\ NA YE ${ }^{1}$, ZHEN ZHANG $^{1}$, YUXIN PANG ${ }^{1}$, JIPING $^{1}{ }^{1}$ and $\mathrm{HE} \mathrm{WU}^{1}$ \\ Departments of ${ }^{1}$ Pathology and ${ }^{2}$ Endocrinology, The First Affiliated Hospital of Harbin Medical University, \\ Harbin, Heilongjiang 150001, P.R. China
}

Received September 22, 2015; Accepted October 5, 2016

DOI: $10.3892 / \mathrm{mmr} .2016 .5925$

\begin{abstract}
Stroke is a life-threatening disease that results in significant disability in the human population. Despite the advances in current stroke therapies, a host of patients do not benefit from the conventional treatments. Thus, more effective therapies are required. It has been previously reported that leucine-rich- $\alpha 2$-glycoprotein 1 (LRG1) is crucial during the formation of new blood vessels in retinal diseases. However, the function of LRG1 in the brain during the neovessel growth process following ischemic stroke has not been fully elucidated and the mechanism underlying its effect on angiogenesis remains unclear. The purpose of the current study was to demonstrate whether LRG1 may promote angiogenesis through the transforming growth factor (TGF)- $\beta 1$ signaling pathway in ischemic rat brain following middle cerebral artery occlusion (MCAO). In the present study, the spatial and temporal expression of LRG1, TGF- $\beta 1$, vascular endothelial growth factor (VEGF) and angiopoietin-2 (Ang-2) were detected in ischemic rat brain following MCAO using reverse transcription-quantitative polymerase chain reaction (RT-qPCR), western blot analysis and immunohistochemistry. CD34 immunohistochemistry staining was used as an indicator of microvessel density (MVD). The RT-qPCR and western blotting results revealed that the levels of LRG1 and TGF- $\beta 1$ mRNA and protein expression were significantly increased as early as 6 and $12 \mathrm{~h}$ after MCAO $(\mathrm{P}<0.05)$, respectively, peaked at 3 days and persisted at significantly higher level until 14 days, in comparison with the control group. Additionally, VEGF and Ang-2 were also increased following MCAO. Furthermore, the immunohistochemistry results suggested that the MVD was increased following MCAO. In addition, the results also
\end{abstract}

Correspondence to: Professor Jiping Qi or Professor $\mathrm{He} \mathrm{Wu}$, Department of Pathology, The First Affiliated Hospital of Harbin Medical University, 23 Youzheng Street, Nangang, Harbin, Heilongjiang 150001, P.R. China

E-mail: qijiping2003@163.com

E-mail: wuher_2008@hotmail.com

Key words: stroke, LRG1, TGF- $\beta 1$, angiogenesis revealed that the percentage of LRG1-positive cells was positively correlated with the percentage of TGF- $\beta 1$-positive cells, and the percentage of LRG1-positive and TGF- $\beta 1$-positive cells had a positively correlation with the MVD. Taken together, the present study indicated that LRG1 may promote angiogenesis through upregulating the TGF- $\beta 1$ signaling pathway in ischemic rat brain following MCAO. This may provide a potential therapeutic target for the treatment of ischemic stroke.

\section{Introduction}

Stroke, a life-threatening condition, is the second leading cause of death worldwide (1). With the advancement of therapeutic strategies, the relative rate of mortality from stroke has declined. However, it still carries a considerable emotional and economic burden. Brain repair following stroke requires various processes, including neurogenesis, angiogenesis and synaptogenesis in the areas around the infarction (2-4). The formation of new blood vessels by angiogenesis is a key feature of stroke. Previously, a multitude of essential angiogenic inducers, including angiopoietin-2 (Ang-2), vascular endothelial growth factor (VEGF), fatty acid binding protein-4, glucose-6-phosphate isomerase and neuropilin-1, were reported to promote neovascularization following stroke (5-7).

Leucine-rich $\alpha 2$-glycoprotein 1 (LRG1) was initially identified as a secreted glycoprotein in human serum by Haupt and Baudner (8) in 1977. It consists of a single polypeptide chain, which includes two intrachain disulfide bonds with 312 amino acid residues (9). LRG1 is a highly conserved member of leucine-rich repeat (LRR) family of proteins, several of which are involved in protein-protein interactions, signaling transduction, cell adhesion, cell survival, cell apoptosis, cell metastasis, DNA transcription, DNA repair and RNA processing (10-13). Zhang et al (14) reported that LRG1 was involved in the inhibition of hepatocellular carcinoma (HCC) metastasis and may function as a novel metastasis suppressor in HCC. Additionally, the function of LRG1 in tumors was investigated, and indicated that LRG1 was associated with multiple types of tumor, including ovarian cancer, glioblastoma and squamous cell lung cancer (15-18). Furthermore, certain previous studies reported that LRG1 is involved in various diseases, including inflammatory diseases, heart failure, arterial stiffness, endothelial dysfunction and peripheral arterial disease (19-23). 
Previously, LRG1 expression in the brain during aging and neurodegenerative diseases, including idiopathic normal pressure hydrocephalus, Parkinson's disease with dementia, dementia with Lewy bodies, progressive nuclear palsy and Alzheimer's disease was investigated $(24,25)$. LRG1 was also considered as a novel biomarker of neurodegenerative disease in human cerebrospinal fluid and may cause neurodegeneration in mouse cerebral cortex $(24,25)$.

Wang et al (26) reported that, as a novel angiogenic factor, LRG1 was significantly elevated in models of retinal neovascularization and expression was restricted almost exclusively to the vasculature system. Increased LRG1 was also observed in a mouse model of choroidal neovascularization compared with control groups, whereas antibody blockade of LRG1 reduced lesion sizes during the progression of choroidal neovascularization (26). The results suggested that LRG1 was a potential therapeutic target for the treatment of macular degeneration (26). Furthermore, the investigation demonstrated that LRG1 promoted neovascularization through the transforming growth factor (TGF)- $\beta 1$ signaling pathway in pathological blood vessel formation (26). In addition, LRG1 overexpression induced cell migration and bound to TGF- $\beta 1$ in endothelial venules (27). The previous studies indicated that LRG1 may be a potential therapeutic target for pathological de novo blood vessel formation. However, whether LRG1 has a critical role in the brain during angiogenesis following ischemic stroke and the mechanism underlying its promotion of neovascularization is remains unknown. In the present study, the changes of LRG1, TGF- $\beta 1$, VEGF and Ang- 2 a rat model of middle cerebral artery occlusion (MCAO) were determined. The results demonstrated that LRG1 may promote angiogenesis through upregulating the TGF- $\beta 1$ signaling pathway in ischemic rat brain after MCAO.

\section{Materials and methods}

Animals and MCAO. Adult male Sprague-Dawley rats weighing 200-250 g were purchased from the Center for Experimental Animals, the Second Affiliated Hospital of Harbin Medical University (Harbin, China). Animals were housed at a controlled temperature $\left(23^{\circ} \mathrm{C}\right)$ and humidity $(50 \%)$, under a 12-h light/dark cycle with access to food and water ad libitum throughout the experiment. All experiments were approved by the Institutional Animal Care and the Ethics Committee of Harbin Medical University.

Rats were divided randomly into 2 groups: the control and MCAO groups. In the control group $(n=6)$, no surgical procedure was performed. For the rat model of MCAO, rats were anesthetized with $10 \%$ chloral hydrate $(400 \mathrm{mg} / \mathrm{kg}$; intraperitoneal injection; Zhanyun Institute of Biotechnology, Shanghai, China) and a line model (diameter $=0.234 \mathrm{~mm}$ ) was inserted into the internal carotid artery to block the middle cerebral artery as previously described (28). Brain tissue collection was performed postoperatively at $2 \mathrm{~h}, 6 \mathrm{~h}, 12 \mathrm{~h}, 1$ day, 3 days, 7 days and 14 days ( $n=6$ at each time point) to collect infarcted brain samples for quantitative polymerase chain reaction (qPCR), western blot analysis and immunohistochemical staining at each time interval. The rats were anesthetized and sacrificed with $10 \%$ chloral hydrate $(800 \mathrm{mg} / \mathrm{kg}$; intraperitoneal injection) at each of the time points, and the rat brain was perfused with $4 \%$ paraformaldehyde (Zhanyun Institute of Biotechnology).

Reverse transcription- $q P C R(R T-q P C R)$. Total mRNA was extracted from control or ischemic rat brains using TRIzol reagent (Invitrogen; Thermo Fisher Scientific, Inc., Waltham, MA, USA) according to the manufacturer's instructions. The purity of mRNA samples was detected using the NanoDrop 2000 spectrophotometer (Thermo Fisher Scientific, Inc., Wilmington, DE, USA). cDNA was synthesized using the Transcriptor First Stand cDNA Synthesis kit (Roche Diagnostics, Basel, Switzerland). qPCR was performed using SYBR Green (Roche Diagnostics) on a thermocycler. The primers used are listed as follows: LRG1, forward 5'-GCATCAAGGGAGAAC CCTGT-3', reverse 5'-CGTGCTTCCCTTAACCGACT-3'; TGF- $\beta 1$, forward 5'-CAGTGGCTGAACCAAGGAGA-3', reverse 5'-GGAAGGGTCGGTTCATGTCA-3'; VEGF, forward 5'-CTGCTCTCTTGGGTGCACT-3', reverse 5'-ATA CACTATCTCATCGGGGTACT-3'; Ang-2. forward 5'-TTG CGACCCCTTCAACTCTG-3', reverse 5'-CCCTTGGGC TTGGCATCATA-3'; GAPDH, forward 5'-GCATCTTCT TGT GCAGTGCC-3', reverse 5'-TACGGCCAAATCCGT TCACA-3'. The samples were amplified out using a Smart Cycler (Cepheid, Inc., Sunnyvale, CA, USA) as follows: Denatured at $95^{\circ} \mathrm{C}$ for $2 \mathrm{~min}, 40$ cycles of amplification $\left(95^{\circ} \mathrm{C}\right.$ for $20 \mathrm{sec}, 60^{\circ} \mathrm{C}$ for $30 \mathrm{sec}$ and $72^{\circ} \mathrm{C}$ for $20 \mathrm{sec}$ ), and a final extension at $72^{\circ} \mathrm{C}$ for $10 \mathrm{~min}$. Expression data were normalized to GAPDH mRNA expression. Data were calculated using the $2^{-\Delta \Delta C q}$ method (29).

Western blotting. Tissues were obtained from control or ischemic rat brains ( $n=6 /$ group) and total cell lysates were prepared using lysis buffer (Beyotime Institute of Biotechnology, Haimen, China). Protein concentration was measured using the bicinchoninic acid method with bovine serum albumin (Baoman Institute of Biotechnology, Shanghai, China) as the standard (30). Equal amounts (50-100 $\mu \mathrm{g})$ of whole cell lysates were resolved by $8-12 \%$ sodium dodecyl sulfate-polyacrylamide gel electrophoresis and transferred to polyvinylidene difluoride membranes (EMD Millipore, Billerica, MA, USA). The membrane was blocked with TBS-0.1\% Tween 20 (TBS-T) containing 5\% skim milk at room temperature for $1 \mathrm{~h}$. The membrane was then incubated with monoclonal mouse anti-mouse LRG1 (1:50; cat. no. sc-390920), polyclonal rabbit anti-human TGF- $\beta 1$ (1:100; cat. no. sc-146), polyclonal rabbit anti-human Ang-2 (1:200; cat. no. sc-20718) and monoclonal mouse anti-human VEGF (1:200; cat. no. sc-7269) primary antibody (Santa Cruz Biotechnology, Inc., Dallas, TX, USA) diluted in blocking solution at $4^{\circ} \mathrm{C}$ overnight and washed with TBS-T three times every $10 \mathrm{~min}$, followed by incubation with goat anti-mouse or goat anti-rabbit secondary antibody $(1: 2,000$; cat. nos. sc-2031 and sc-2030, respectively; Santa Cruz Biotechnology, Inc.) at room temperature for $1 \mathrm{~h}$. Subsequent to washing in TBS-T, the protein bands were visualized using enhanced chemiluminescence kits (Beyotime Institute of Biotechnology). Blots were stained with monoclonal mouse anti-human $\beta$-actin antibody (1:1,000; cat. no. TA-09; Zhongshan Biotechnology Co., Ltd., Beijing, China) as an internal control for the amount of target proteins. Band intensity of 
Table I. Percentage of LRG1, TGF- $\beta 1$, VEGF, Ang-2-positive cells and MVD in ischemic penumbra of rat brain at different time points following middle cerebral artery occlusion.

\begin{tabular}{llccrc}
\hline Time & LRG1 $^{+}(\%)$ & TGF- $\beta 1^{+}(\%)$ & VEGF $^{+}(\%)$ & Ang-2 $(\%)$ & MVD $^{2}$ \\
\hline Control & $52.64 \pm 11.35$ & $6.24 \pm 3.23$ & $12.21 \pm 6.68$ & $15.12 \pm 6.08$ & $9.83 \pm 3.71$ \\
$2 \mathrm{~h}$ & $53.19 \pm 6.68$ & $6.06 \pm 2.88$ & $27.36 \pm 9.18^{\mathrm{a}}$ & $29.84 \pm 10.99$ & $10.63 \pm 2.09$ \\
$6 \mathrm{~h}$ & $55.11 \pm 12.73$ & $14.51 \pm 4.44$ & $37.11 \pm 7.08^{\mathrm{a}}$ & $38.28 \pm 10.21^{\mathrm{a}}$ & $10.77 \pm 3.69$ \\
$12 \mathrm{~h}$ & $59.02 \pm 7.98^{\mathrm{a}}$ & $22.02 \pm 3.99^{\mathrm{a}}$ & $54.24 \pm 13.13^{\mathrm{a}}$ & $36.87 \pm 6.72^{\mathrm{a}}$ & $13.20 \pm 3.54^{\mathrm{a}}$ \\
1 days & $63.65 \pm 13.37^{\mathrm{a}}$ & $39.59 \pm 6.14^{\mathrm{a}}$ & $56.98 \pm 14.17^{\mathrm{a}}$ & $46.78 \pm 9.90^{\mathrm{a}}$ & $21.53 \pm 4.22^{\mathrm{a}}$ \\
3 days & $68.43 \pm 6.05^{\mathrm{a}}$ & $66.90 \pm 9.66^{\mathrm{a}}$ & $76.23 \pm 7.37^{\mathrm{a}}$ & $57.30 \pm 9.22^{\mathrm{a}}$ & $26.63 \pm 4.18^{\mathrm{a}}$ \\
7 days & $66.38 \pm 7.22^{\mathrm{a}}$ & $58.05 \pm 7.91^{\mathrm{a}}$ & $71.36 \pm 6.86^{\mathrm{a}}$ & $38.11 \pm 6.98^{\mathrm{a}}$ & $24.83 \pm 5.06^{\mathrm{a}}$ \\
14 days & $56.77 \pm 11.31$ & $45.77 \pm 10.00^{\mathrm{a}}$ & $57.46 \pm 11.75^{\mathrm{a}}$ & $32.74 \pm 6.58^{\mathrm{a}}$ & $14.83 \pm 3.30^{\mathrm{a}}$ \\
\hline
\end{tabular}

${ }^{\text {aP }}<0.05$ vs. control; LRG1, leucine-rich- $\alpha 2$-glycoprotein 1 ; TGF- $\beta 1$; transforming growth factor- $\beta 1$; VEGF, vascular endothelial growth factor; Ang-2, angiopoietin-2; MVD, microvessel density.

each sample was determined using a UVP iBox 500 imaging system (UVP, Inc., Upland, CA, USA)

Immunohistochemical staining. Tissue samples from control or ischemic rat brains were fixed in $4 \%$ formalin at $25^{\circ} \mathrm{C}$ for $36 \mathrm{~h}$ and embedded in paraffin, then were cut into $4 \mu \mathrm{m}$ thick sections. Paraffin sections were dewaxed with xylene and rehydrated by graded concentrations of ethanol. Then endogenous peroxidase was blocked by $0.3 \%$ hydrogen peroxide for $10 \mathrm{~min}$. The sections were rehydrated with EDTA ( $\mathrm{pH} \mathrm{9.0)} \mathrm{at} 120^{\circ} \mathrm{C}$ for $2 \mathrm{~min}$ and cooled for $40 \mathrm{~min}$ at room temperature. Subsequent to blocking for $30 \mathrm{~min}$ with bovine serum albumin, primary antibody to monoclonal mouse anti-mouse LRG1 (1:50; cat. no. sc-390920), polyclonal rabbit anti-human TGF- $\beta 1$ (1:100; cat. no. sc-146), polyclonal rabbit anti-human Ang-2 (1:200; cat. no. sc-20718) and monoclonal mouse anti-human VEGF (1:200; cat. no. sc-7269) primary antibody (Santa Cruz Biotechnology, Inc.) and CD34 (1:200; cat. no. ab185732; Abcam, Cambridge, MA, USA) were incubated overnight at $4^{\circ} \mathrm{C}$ in humidified chambers (Santa Cruz Biotechnology, Inc.). The goat anti-mouse/rabbit secondary antibody (cat. no. PV-9000; Zhongshan Biotechnology Co., Ltd., Beijing, China) was incubated for $30 \mathrm{~min}$ at room temperature. Diaminobenzidine was then used to detect positive staining (cat. no. ZLI-9017, Zhongshan Biotechnology Co., Ltd.,). Then sections were counterstained with hematoxylin. Sections were viewed under a light microscope and images were captured with a CCD camera (DMI6000B; Leica Microsystems GmbH, Wetzlar, Germany) using imaging-processing software (LAS AF6000; Leica Microsystems GmbH). The mean percentage of positively-stained cells in 5 high power fields per sample (magnification, x200) of each group was used as the final value.

Microvessel density (MVD) analysis. CD34 staining was performed as an indicator of MVD. The density of microvessels was assessed according to the criteria proposed by Weidner et al (31). Any endothelial cells or endothelial cell clusters brown-stained in the cytoplasm were considered as a countable microvessel. The average number of microvessels in 5 high-power fields/sample (x200 magnification) of each group were used as the final value. The assessments were performed by a single pathologist who was blinded to the data.

Statistical analysis. SPSS 13.0 (SPSS, Inc., Chicago, IL, USA) was used for the statistical analysis. The data are presented as the mean \pm standard deviation. Differences among the means were analyzed using one-way analysis of variance and Student-Newman-Keuls method. Spearman rank correlation coefficient test analysis was performed to examine the correlations between LRG1, and TGF- $\beta 1$, Ang-2, VEGF and MVD. $\mathrm{P}<0.05$ was considered to indicate a statistically significant difference.

\section{Results}

Expression of LRG1 was increased in ischemic rat brain following MCAO. To demonstrate whether LRG1 was involved in angiogenesis in ischemic rat brain following MCAO, the spatial and temporal expression of LRG1 was detected. The results revealed that LRG1 mRNA was significantly increased compared with the level in the control as early as $6 \mathrm{~h}(\mathrm{P}<0.05)$, peaked at 3 days after MCAO, then gradually decreased, however the level of LRG1 at 14 days remained significantly higher than the control groups $(\mathrm{P}<0.05$; Fig. 1A). The level of LRG1 protein was significantly elevated compared with the control at $6 \mathrm{~h}(\mathrm{P}<0.05)$, reached a maximum at 3 days, persisting at a higher level compared with the control until 14 days after MCAO ( $\mathrm{P}<0.05$; Fig. 1B). The immunohistochemistry staining indicated that LRG1 protein was located in the cellular nucleus (Fig. 1C). LRG1 was expressed in the endothelial cells of microvessels, and also in the astrocyte-like cells (Fig. 1C). Furthermore, the percentage of LRG1-positive cells was significantly higher than the control at $12 \mathrm{~h}$ in the ischemic penumbra of the rat brain following MCAO $(\mathrm{P}<0.05)$, peaked at 3 days and gradually declined to the normal level at 14 days (Table I).

Expression of TGF- $\beta 1$ is upregulated in ischemic rat brain following MCAO. To detect whether TGF- $\beta 1$ is associated with angiogenesis in rat brain following MCAO, the spatial and temporal expression of TGF- $\beta 1$ was examined. The results 
A
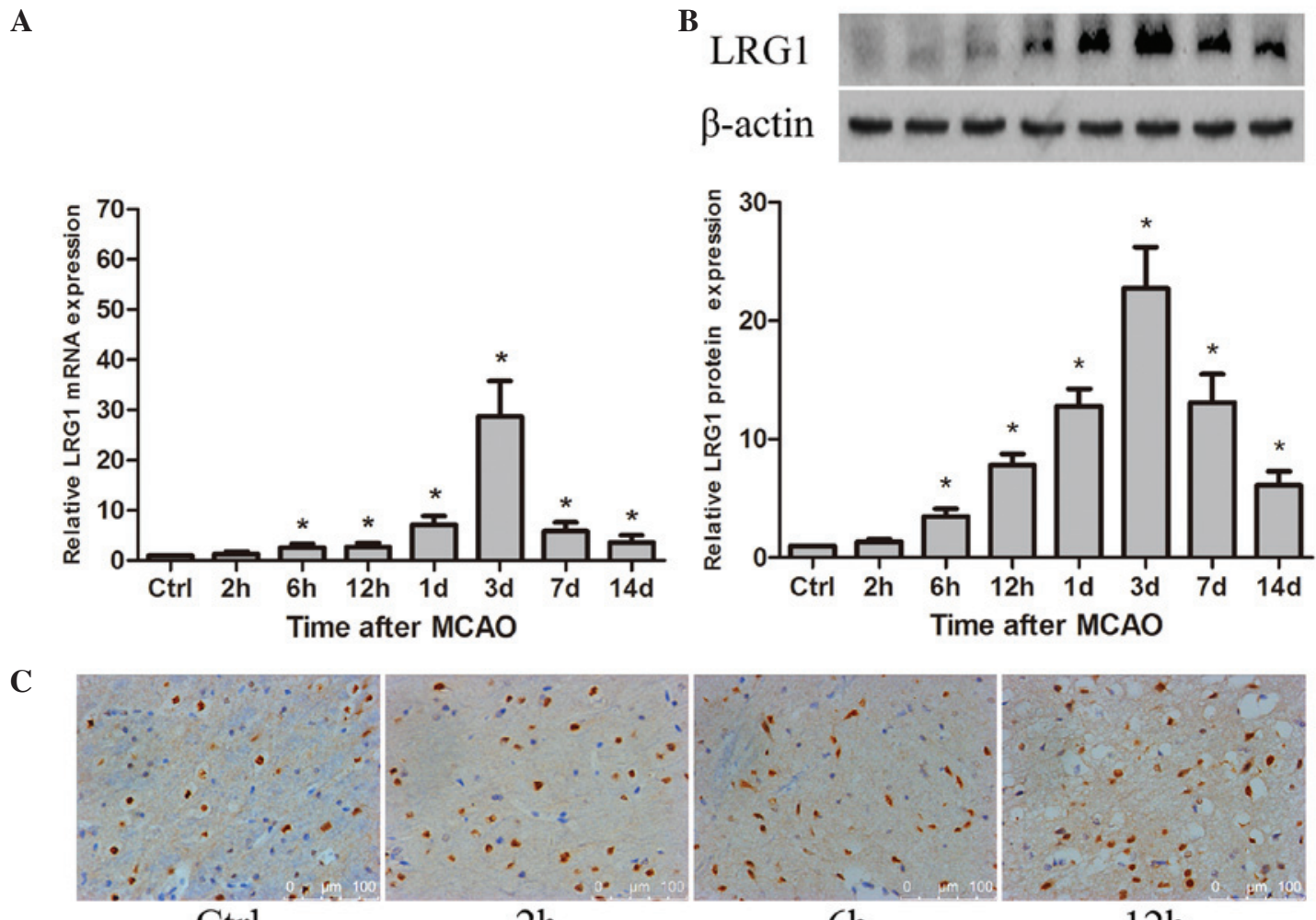

$6 \mathrm{~h}$

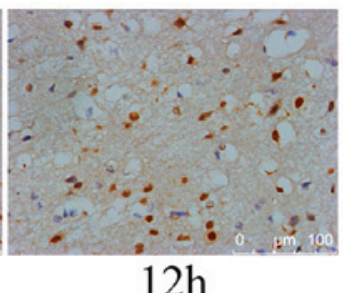

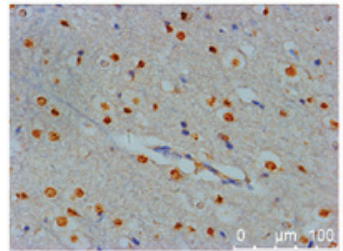

$1 \mathrm{~d}$

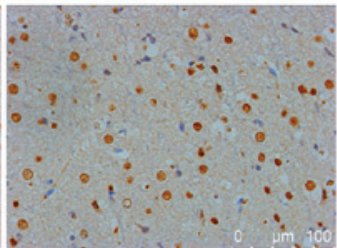

$3 \mathrm{~d}$

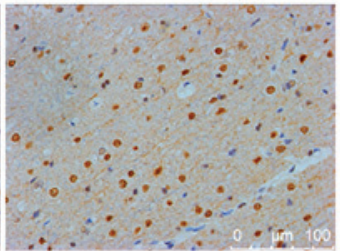

$7 \mathrm{~d}$

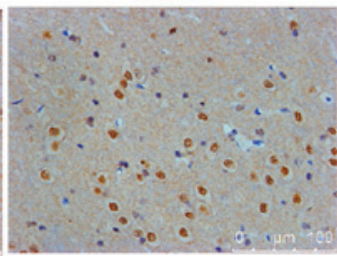

$14 d$

Figure 1. Changes of LRG1 mRNA and protein in ischemic rat brain following MCAO. (A) Expression of LRG1 mRNA in ischemic rat brain at different time points following MCAO. (B) Expression of LRG1 protein in ischemic rat brain at different time points following MCAO and graph presenting the LRG1 protein expression relative to $\beta$-actin at different time points following MCAO ( $\mathrm{n}=6$ per group). Values are presented as the mean \pm standard deviation. ${ }^{*} \mathrm{P}<0.05 \mathrm{vs}$. ctrl. (C) Immunohistochemical staining for LRG1 protein in the ischemic boundary area of rat brain at the different time points after MCAO (n=6 per group). LRG1, leucine-rich- $\alpha 2$-glycoprotein 1 ; Ctrl, control; MCAO, middle cerebral artery occlusion.

demonstrated that TGF- $\beta 1$ mRNA was significantly increased at $12 \mathrm{~h}$ compared with the control $(\mathrm{P}<0.05)$ and reached a maximum at 3 days after MCAO, persisting at a significantly higher level until 14 days $(\mathrm{P}<0.05$; Fig. $2 \mathrm{~A})$. TGF- $\beta 1$ protein was significantly upregulated at $12 \mathrm{~h}$ compared with the control $(\mathrm{P}<0.05)$, peaked at 3 days after $\mathrm{MCAO}$, and remained a significantly higher level until 14 days $(\mathrm{P}<0.05$; Fig. $2 \mathrm{~B})$. The immunohistochemistry staining indicated that TGF- $\beta 1$ protein was distributed to the cellular nucleus (Fig. 2C). Compared with the control group, the percentage of TGF- $\beta 1$-positive cells was significantly increased at $12 \mathrm{~h}(\mathrm{P}<0.05)$, peaked at 3 days in the ischemic penumbra of the rat brain following MCAO, persisted at a significantly higher level at 7 day $(\mathrm{P}<0.05)$ and gradually decreased until 14 days (Table I).

Expression of angiogenic factors, VEGF and Ang-2, are elevated in ischemic rat brain following MCAO. As the angiogenic factors, the spatial and temporal expression of VEGF and Ang- 2 were examined in ischemic rat brain following MCAO. The results suggested that VEGF mRNA was significantly elevated compared with the control levels as early as $6 \mathrm{~h}$ $(\mathrm{P}<0.05)$, reached a peak at $12 \mathrm{~h}$, and remained a significantly higher level until 1 day after MCAO $(\mathrm{P}<0.05)$, then decreased gradually (Fig. 3A). VEGF protein was significantly increased compared with the control at $12 \mathrm{~h}(\mathrm{P}<0.05)$, peaked at 1 days, persisted at a higher level until 7 days $(\mathrm{P}<0.05)$, then declined to the normal level (Fig. 3B). Immunohistochemistry demonstrated that VEGF protein was predominantly located in the cellular cytoplasm of neuron-like and glial-like cells in the ischemic penumbra of the rat brain (Fig. 3C). Compared with the control group, the percentage of VEGF-positive cells was significantly higher in the ischemic penumbra of the rat brain at $2 \mathrm{~h}$ after MCAO $(\mathrm{P}<0.05)$, reached a maximum at 3 days and remained at a significantly higher level at 14 days $(\mathrm{P}<0.05$; Table I).

The results also revealed that Ang-2 mRNA was significantly increased at 1 day after MCAO compared with the control $(\mathrm{P}<0.05)$, reached a maximum at $3 \mathrm{~d}$ and remained a higher level at 7 days after MCAO $(\mathrm{P}<0.05)$, then gradually declined to the normal baseline (Fig. 3A). The Ang-2 protein 
A

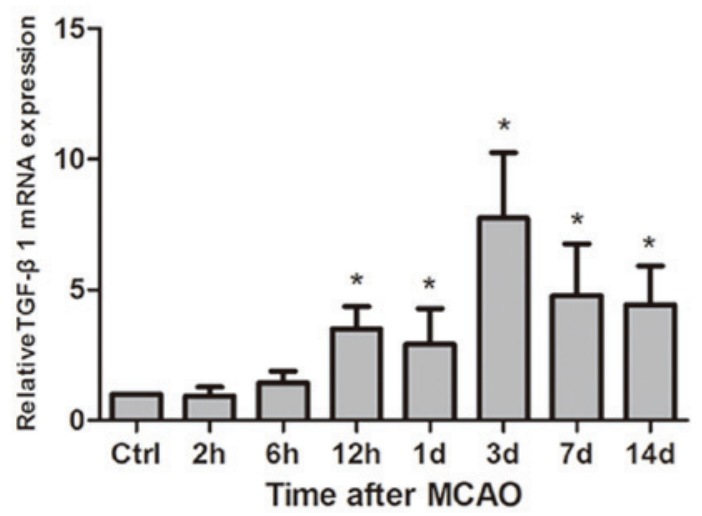

C

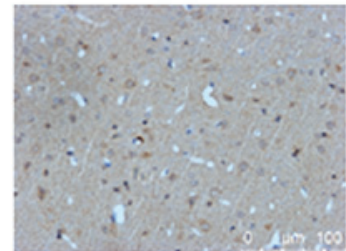

Ctrl

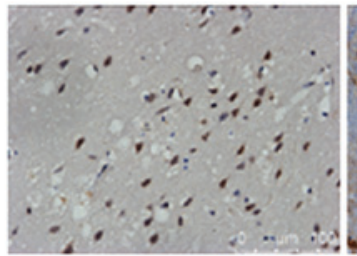

ld

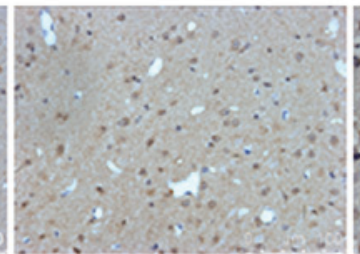

$2 \mathrm{~h}$

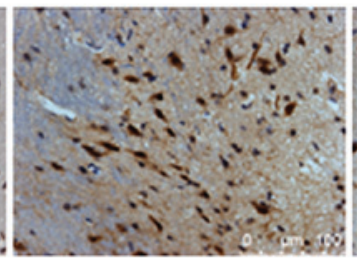

$3 \mathrm{~d}$

B
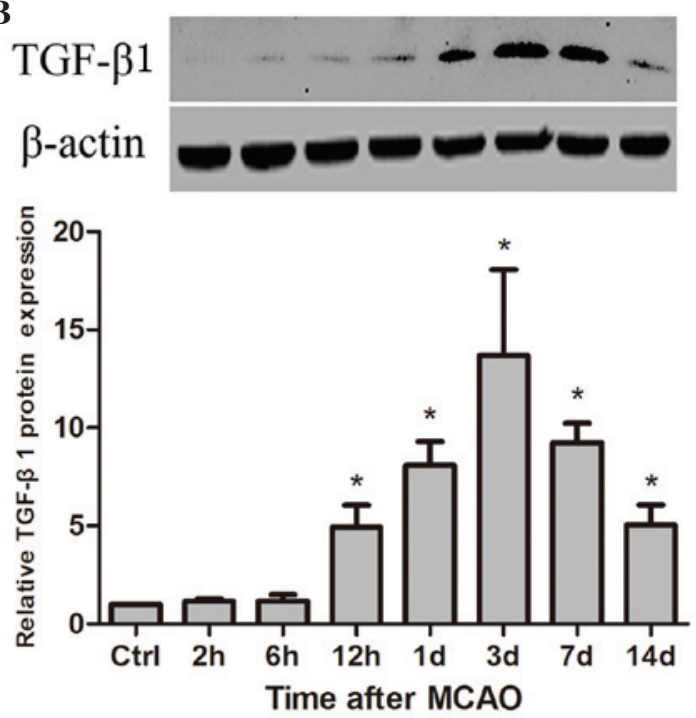

Time after MCAO

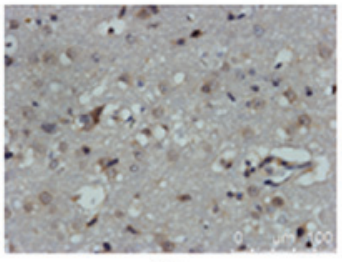

$6 \mathrm{~h}$

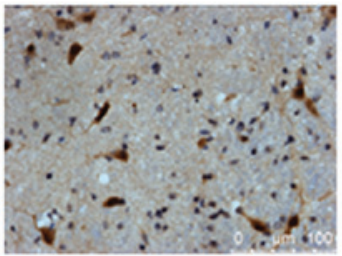

$7 d$

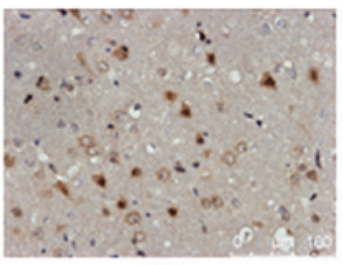

$12 \mathrm{~h}$

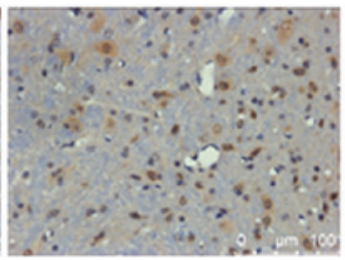

$14 d$

Figure 2. Changes of TGF- $\beta 1 \mathrm{mRNA}$ and protein in ischemic rat brain following MCAO. (A) Expression of TGF- $\beta 1 \mathrm{mRNA}$ in ischemic rat brain at different time points following MCAO. (B) Expression of TGF- $\beta 1$ protein in ischemic rat brain at different time points following MCAO and a bar graph presenting the TGF- $\beta 1$ protein expression relative to $\beta$-actin at different time points following MCAO ( $n=6$ per group). Values are presented as the mean \pm standard deviation. ${ }^{*} \mathrm{P}<0.05$ vs. ctrl. (C) Immunohistochemical staining for TGF- $\beta 1$ protein in the ischemic boundary area of rat brain at the different time points after $\mathrm{MCAO}$ ( $\mathrm{n}=6$ per group). TGF- $\beta$, transforming growth factor; Ctrl, control; MCAO, middle cerebral artery occlusion.

was significantly upregulated at 1 day compared with the control $(\mathrm{P}<0.05)$, peaked at 3 days after $\mathrm{MCAO}$, persisting at a significantly higher level until 7 days $(\mathrm{P}<0.05)$, and declined to the baseline (Fig. 3B). Immunohistochemistry demonstrated that Ang-2 protein was predominantly located in the cellular cytoplasm of neuron-like and glial-like cells in the ischemic penumbra (Fig. 3D). Furthermore, the percentage of Ang-2-positive cells was significantly higher in the ischemic penumbra of the rat brain at $6 \mathrm{~h}$ after MCAO compared with the control $(\mathrm{P}<0.05)$, reached a peak at 3 days, still persisted at a significantly higher level until 14 days $(\mathrm{P}<0.05$; Table I).

Formation of blood vessels in response to the ischemic rat brain following $M C A O$. Ischemic rat brains at the different time points after MCAO ( $\mathrm{n}=6$ per group) were paraffin-embedded and formalin-fixed. Sections ( $4 \mu \mathrm{m}$ thick) from the brain tissues were used to detect the expression of CD34 protein. CD34 staining was performed as an indicator of MVD (Fig. 4A). The average number of microvessels in 5 high-power fields/sample (x200 magnification) of each group was used as the final value. The results indicated that the mean value of MVD was significantly increased compared with the control at $12 \mathrm{~h}(\mathrm{P}<0.05)$, reached a peak at 3 days, and remained a significantly increased level until 14 days $(\mathrm{P}<0.05$; Fig. 4B).

Using Spearman correlation analysis, the immunohistochemistry results demonstrated that the percentage of LRG1-positive cells was positively correlated with the percentage of TGF- $\beta 1$-positive, VEGF-positive, Ang-2-positive cells and the MVD (Table II). Furthermore, the results also suggested that TGF- $\beta 1$-positive cells had a positively correlation with the percentage of VEGF-positive cells and the MVD (Table II). In addition, the percentage of VEGF-positive cells and the percentage of Ang-2-positive cells were positively correlated with the MVD (Table II).

\section{Discussion}

Stroke is subdivided into ischemic, intracerebral putic hemorrhagic and subarachnoid hemorrhagic stroke (32). It is a serious 
B

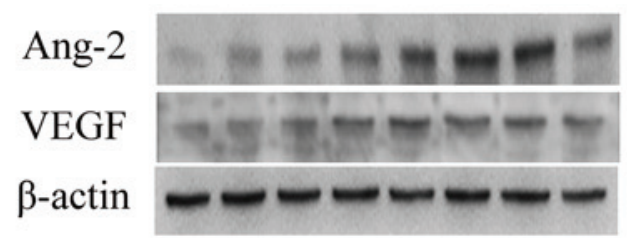

A
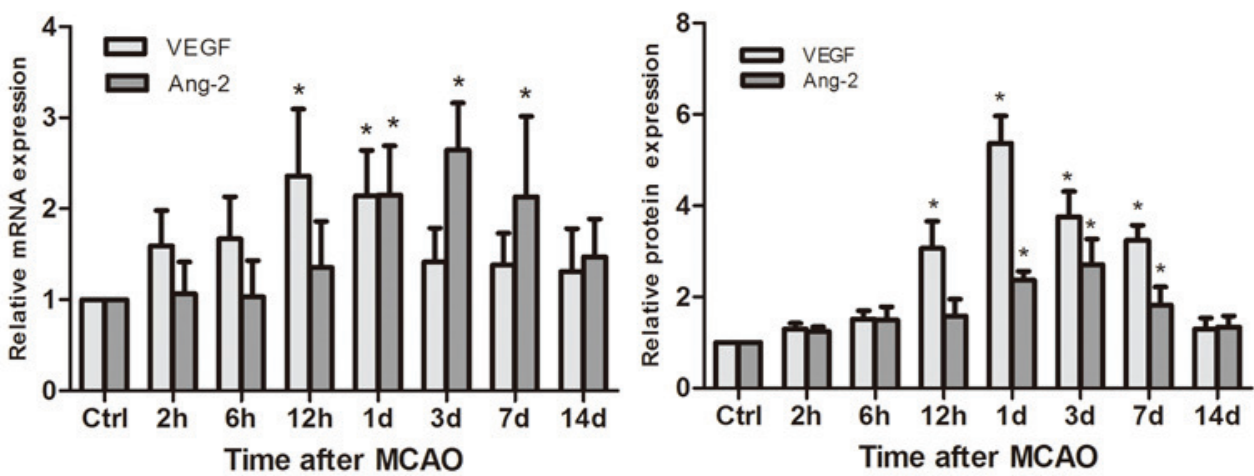

C
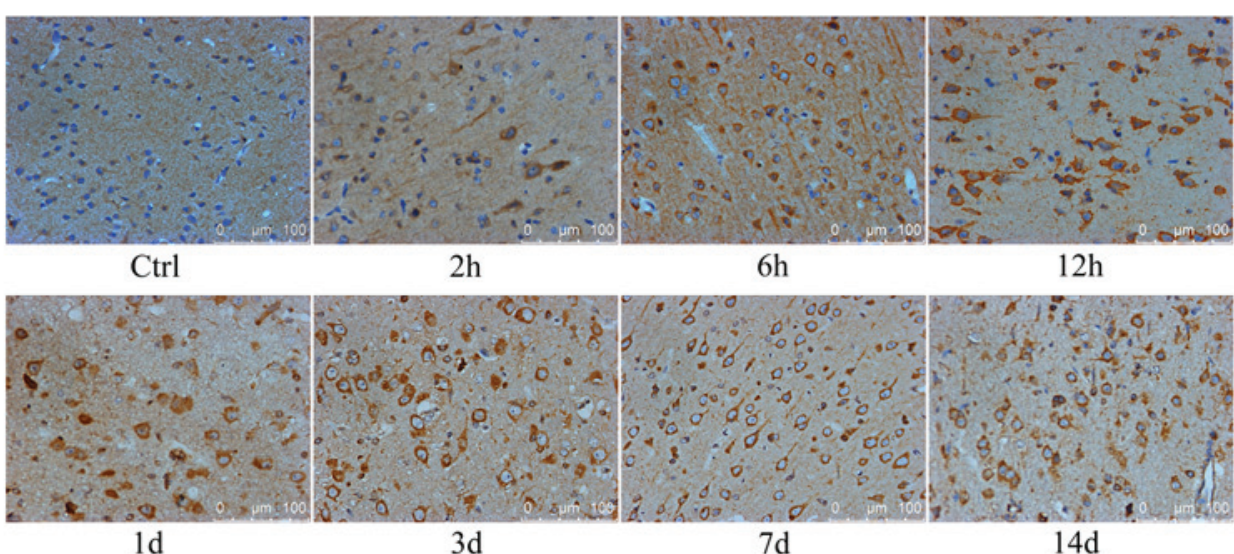

D
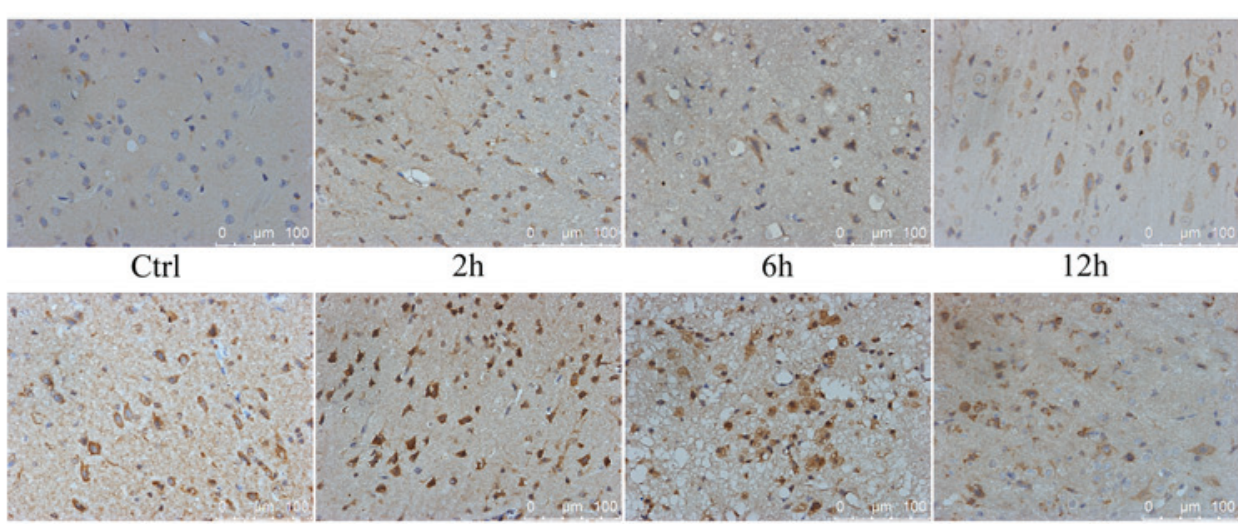

$1 \mathrm{~d}$

$3 \mathrm{~d}$

$7 d$

$14 \mathrm{~d}$

Figure 3. Changes of VEGF and Ang-2 mRNA and protein in ischemic rat brain following MCAO. (A) Expression of VEGF and Ang-2 mRNA in ischemic rat brain at different time points following MCAO. (B) Expression of VEGF and Ang-2 protein in ischemic rat brain at different time points following MCAO and bar graph presenting the VEGF and Ang-2 protein expression relative to $\beta$-actin at different time points following MCAO (n=6 per group). Values are presented as the mean \pm standard deviation. " $\mathrm{P}<0.05$ vs. ctrl. (C) Immunohistochemical staining for VEGF protein in the ischemic boundary area of rat brain at the different time points after MCAO (n=6 per group). (D) Immunohistochemical staining for Ang-2 protein in the ischemic boundary area of rat brain at the different time points after MCAO ( $\mathrm{n}=6$ per group). VEGF, vascular endothelial growth factor; Ang-2, angiopoietin-2; Ctrl, control. MCAO, middle cerebral artery occlusion.

cause of human mortality and disability. Opening the collateral circulation and recovering the perfusion of blood flow in the ischemic penumbra following stroke plays is crucial for protecting the structure and function of the ischemic brain tissue $(33,34)$. Therefore, it is important to investigate the mechanisms of angiogenesis following stroke.
A novel angiogenic factor, LRG1, is a highly conserved member of the LRR family of proteins. It is a secreted glycoprotein. The LRR structure of LRG1 has been proposed to be important for its biological function (20). It regulates diverse biological processes, including cell proliferation, cell apoptosis, cell mobility and cell adhesion $(10,11,13)$. 
Table II. Correlations of LRG1, TGF- $\beta 1$, VEGF, Ang-2-positive cells and MVD in ischemic penumbra of rat brain following middle cerebral artery occlusion.

\begin{tabular}{lccccc}
\hline Parameter & LRG1 $\%$ & TGF- $\beta 1^{+} \%$ & VEGF $^{+} \%$ & Ang-2 $\%$ & MVD \\
\hline LRG1+\% & - & $0.002^{\mathrm{a}}$ & $0.001^{\mathrm{a}}$ & $0.015^{\mathrm{a}}$ & $0.000^{\mathrm{a}}$ \\
TGF- $\beta 1+\%$ & - & - & $0.000^{\mathrm{a}}$ & 0.071 & $0.000^{\mathrm{a}}$ \\
VEGF+\% & - & - & - & 0.058 & $0.000^{\mathrm{a}}$ \\
Ang-2+\% & - & - & - & - & $0.021^{\mathrm{a}}$ \\
\hline
\end{tabular}

${ }^{a} \mathrm{P}<0.05$. Spearman correlation analysis was used to analyze the correction among the proteins. LRG1, leucine-rich- $\alpha 2$-glycoprotein 1 ; TGF- $\beta 1$; transforming growth factor- $\beta 1$; VEGF, vascular endothelial growth factor; Ang-2, angiopoietin-2; MVD, microvessel density.

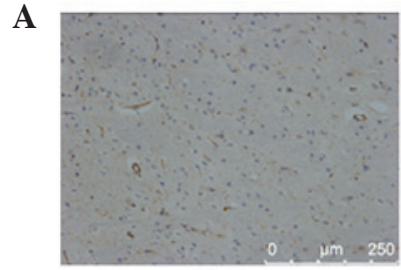

Ctrl

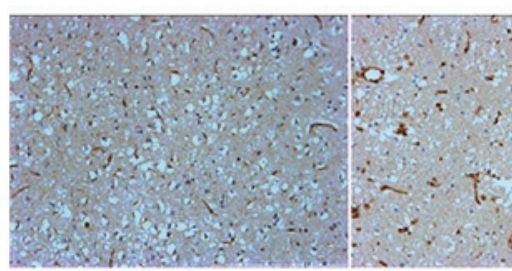

ld

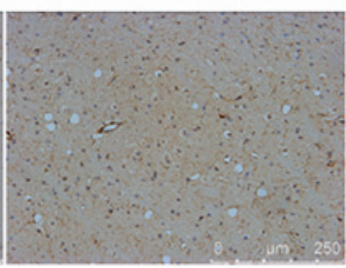

$2 \mathrm{~h}$

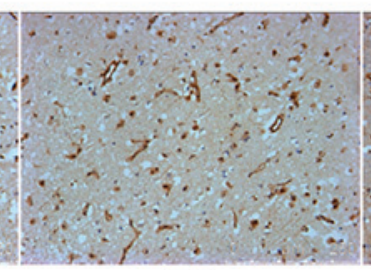

$7 \mathrm{~d}$
$6 \mathrm{~h}$
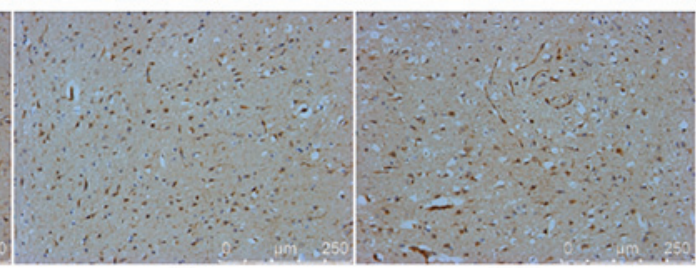

$12 \mathrm{~h}$

B

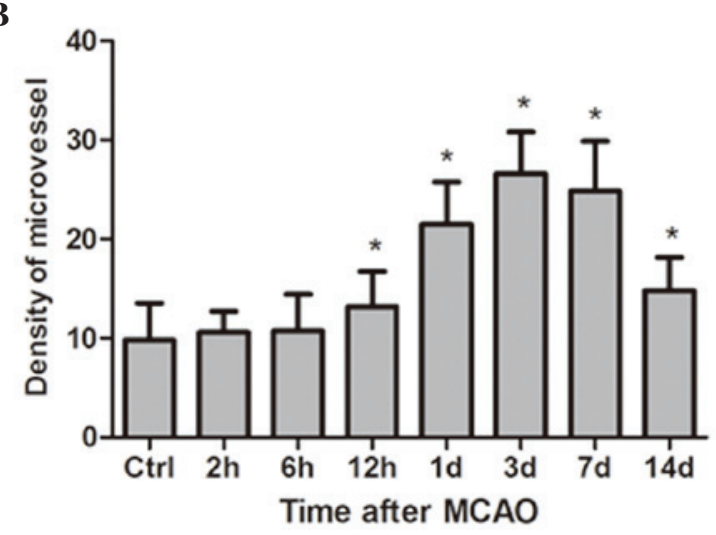

Figure 4. Formation of neovascularization in ischemic rat brain at the different time points following MCAO. (A) Brain sections were immunostained for CD34 to count the the number of microvessels. (B) Bar graph presents the density of microvessels in rat brain at different time points following MCAO. Microvessels were counted from 5 fields of the ischemic penumbra area under a microscope at x 200 magnification ( $\mathrm{n}=6 \mathrm{per}$ group). ${ }^{*} \mathrm{P}<0.05$ vs. ctrl. MCAO, middle cerebral artery occlusion; Ctrl, control.

Wang et al (26) reported that LRG1 expression was significantly increased during retinal neovascular remodeling of mouse eye compared with in the normal mouse retina. The study also observed that the expression of LRG1 was not restricted to the mouse retina, but also expressed in the vasculature of mouse choriocapillaries (26). Consistent with the data, the study reported that LRG1 was expressed in the vessels of retina, breast, skin and intestine in normal adult human at a low level (26). Based on the previous study, LRG1 was declared as a novel regulator of neovascularization with expression restricted almost exclusively to the vasculature system (26). Thus, it was speculated that LRG1 may be involved in the regulation of angiogenesis following stroke. To demonstrate whether LRG1 is involved in cerebral ischemia, the current study detected LRG1 expression in ischemic rat brain at $2 \mathrm{~h}, 6 \mathrm{~h}, 12 \mathrm{~h}, 1$ day, 3 days, 7 days and 14 days after MCAO. The results suggested that LRG1 mRNA and protein were significantly upregulated as early as $6 \mathrm{~h}$ after MCAO and peaked at 3 days, persisting at a significantly higher level compared with control until 14 days (Fig. 1A). In addition to increased LRG1 expression, the mean value of MVD was also significantly increased (Fig. 4A). The above results indicated that LRG1 may promote de novo blood 
formation in ischemic rat brain following MCAO. The blood formation will benefit the recovery of blood flow in the ischemic penumbra, which may protect the ischemic brain from injury. Thus, the data of the current study further indicated that LRG1 may protect the ischemic brain by recovering the blood flow due to the formation of novel blood in the ischemic penumbra.

LRG1 expression has diverse cellular locations, including the nucleus, cytoplasm, plasma membrane, extracellular matrix, serum and cerebrospinal fluid $(12,14,20)$. Nakajima et al (35) reported that LRG1 is distributed throughout the entire brain. Double staining of CD31 and LRG1 revealed marked expression of LRG in the capillaries, and the cells expressing LRG1 exhibited similar morphology to astrocytes (35). The results of the present investigation revealed that LRG1 protein was predominantly located in the cellular nucleus of ischemic rat brain (Fig. 1C). LRG1 was not only expressed in vasculature system, but also in astrocyte-like cells. The results were in accordance with the previous study (35). Thus, we hypothesize that in ischemic rat brain after MCAO, the expression of LRG1 was significantly increased in endothelial and astrocyte cells, and secreted into the extracellular environment, then involved in the regulation of angiogenesis and protected the ischemic brain.

Wang et al (26) reported that in vitreous samples of human subjects with proliferative diabetic retinopathy, in addition to increased LRG1 protein expression, TGF- $\beta 1$ protein level was also significantly upregulated. Furthermore, with increased LRG1 gene expression, the TGF- $\beta 1$ mRNA transcript level was also concomitantly elevated in the models of choroidal and retinal neovascularization (26). Takemoto et al (36) reported that LRG1 potentiated the effect of TGF- $\beta 1$ in Lewis lung carcinoma cells. Furthermore, LRG1 was implicated as an upstream regulator of the TGF- $\beta 1$ signaling pathway in non-small-cell lung carcinoma (37). In addition, LRG1 has a strong affinity with TGF- $\beta 1$ in high endothelial venules (27). These data indicated that LRG1 may act as a modulator of the TGF- $\beta$ signaling pathway. This prompted us to investigate whether LRG1 was involved in angiogenesis via the TGF- $\beta$ signaling pathway in ischemic rat brain following MCAO. In the present study, TGF- $\beta 1 \mathrm{mRNA}$ and protein were significantly increased compared with the control at $12 \mathrm{~h}$ and reached a maximum at 3 days after MCAO, persisting at a significantly higher level until 14 days (Fig. 2A and B). Consistent with increased LRG1 expression, TGF- $\beta 1$ expression was also significantly elevated. This indicated that in ischemic rat brain following MCAO, LRG1 may protect the ischemic rat brain from injury through promoting angiogenesis via upregulating the TGF- $\beta 1$ signaling pathway.

Wang et al (26) demonstrated that in the presence of TGF- $\beta 1$, LRG1 binds to activin A receptor like type 1 (ALK1), a TGF- $\beta$ signaling pathway receptor, and activated its downstream mediators, Smads $(26,38)$, which are involved in the angiogenesis by inducing the expression and secretion of vascular growth factors, including VEGF and Ang-2 $(39,40)$. Angiogenic factors, VEGF and Ang-2, promote the proliferation of endothelial cells and the initiation of angiogenesis (41). In the current study, the levels of VEGF and Ang-2 mRNA and protein expression were significantly increased at $12 \mathrm{~h}$ and 1 day in ischemic rat brain after MCAO, with the peak at 1 day and 3 days, respectively. Then they gradually declined to the baseline. Therefore, we hypothesize that the expression of LRG1 was upregulated in endothelial and astrocyte-like cells and secreted during the angiogenesis process following cerebral ischemia. Additionally, LRG1 bound to the TGF- $\beta 1$ receptor, ALK1, and activated Smads downstream. Then, the ischemic brain secreted angiogenic factors, including VEGF and Ang-2, which promoted angiogenesis.

A recent publication implied that LRG1 was positively correlated with TGF- $\beta$ receptor 1 in cardiac fibrosis (19). In the current study, using Spearman correlation analysis, the immunohistochemistry results revealed that the percentage of LRG1-positive cells was positively correlated with the percentage of TGF- $\beta 1$-positive cells. Furthermore, the percentage of LRG1-positive and TGF- $\beta 1$-positive cells had a positively correlation with the MVD (Table II). The results further indicated that LRG1 may promote angiogenesis through upregulating the TGF- $\beta 1$ signaling pathway. The immunohistochemistry results were consistent with the RT-qPCR and western blot results.

In summary, the results of the present study indicated that in ischemic rat brain following MCAO, LRG1 expression was increased in astrocyte-like cells and secreted from cells, then may have promoted the de novo blood vessel formation by inducing the expression angiogenic factors, including VEGF and Ang-2, through upregulating TGF- $\beta 1$ signaling. In order to fully identify the mechanisms that LRG1 regulating the angiogenesis in ischemic brain, future studies are required.

\section{Acknowledgements}

We would like to thank Mr. Xiang Fang, Mr. Hongda Wang, Ms. Miaomiao Jiang and Ms. Yunhe Gu (Department of Pathology, The First Affiliated Hospital of Harbin Medical University, Harbin, China) for technical support. This study was supported by the Natural Science Fund of China (grant no. 30973106).

\section{References}

1. Lundberg GP and Volgman AS: Burden of stroke in women. Trends Cardiovasc Med 26: 81-88, 2016.

2. Verma V, Samanthapudi K and Raviprakash R: Classic studies on the potential of stem cell neuroregeneration. J Hist Neurosci 25: 123-141, 2016.

3. Esposito E, Hayakawa K, Maki T, Arai K and Lo EH: Effects of postconditioning on neurogenesis and angiogenesis during the recovery phase after focal cerebral ischemia. Stroke 46: 2691-2694, 2015.

4. Zhang ZG and Chopp M: Promoting brain remodeling to aid in stroke recovery. Trends Mol Med 21: 543-548, 2015.

5. Moss A: The angiopoietin: Tie 2 interaction: A potential target for future therapies in human vascular disease. Cytokine Growth Factor Rev 24: 579-592, 2013.

6. Kwon HS, Kim YS, Park HH, Choi H, Lee KY, Lee YJ, Heo SH, Chang DI and Koh SH: Increased VEGF and decreased SDF-1 $\alpha$ in patients with silent brain infarction are associated with better prognosis after first-ever acute lacunar stroke. J Stroke Cerebrovasc Dis 24: 704-710, 2015.

7. Shaikh H, Boudes E, Khoja Z, Shevell M and Wintermark P: Angiogenesis dysregulation in term asphyxiated newborns treated with hypothermia. PLoS One 10: e0128028, 2015.

8. Haupt $\mathrm{H}$ and Baudner S: Isolation and characterization of an unknown, leucine-rich 3.1-S-alpha2-glycoprotein from human serum (author's transl). Hoppe Seylers Z Physiol Chem 358: 639-646, 1977 (In German).

9. Takahashi N, Takahashi Y and Putnam FW: Periodicity of leucine and tandem repetition of a 24 -amino acid segment in the primary structure of leucine-rich alpha 2-glycoprotein of human serum. Proc Natl Acad Sci USA 82: 1906-1910, 1985. 
10. Kobe B and Kajava AV: The leucine-rich repeat as a protein recognition motif. Curr Opin Struct Biol 11: 725-732, 2001.

11. Kobe B and Deisenhofer J: Proteins with leucine-rich repeats. Curr Opin Struct Biol 5: 409-416, 1995.

12. Serada S, Fujimoto M, Terabe F, Iijima H, Shinzaki S, Matsuzaki S, Ohkawara T, Nezu R, Nakajima S, Kobayashi T, et al: Serum leucine-rich alpha-2 glycoprotein is a disease activity biomarker in ulcerative colitis. Inflamm Bowel Dis 18: 2169-2179, 2012.

13. Wong CC, Tse AP, Huang YP, Zhu YT, Chiu DK, Lai RK, Au SL, Kai AK, Lee JM, Wei LL, et al: Lysyl oxidase-like 2 is critical to tumor microenvironment and metastatic niche formation in hepatocellular carcinoma. Hepatology 60: 1645-1658, 2014.

14. Zhang Y, Luo Q, Wang N, Hu F, Jin H, Ge T, Wang C and Qin W: LRG1 suppresses the migration and invasion of hepatocellular carcinoma cells. Med Oncol 32: 146, 2015.

15. Wu J, Yin H, Zhu J, Buckanovich RJ, Thorpe JD, Dai J, Urban N and Lubman DM: Validation of LRG1 as a potential biomarker for detection of epithelial ovarian cancer by a blinded study. PLoS One 10: $0121112,2015$.

16. Zhong D, Zhao S, He G, Li J, Lang Y, Ye W, Li Y, Jiang C and Li X: Stable knockdown of LRG1 by RNA interference inhibits growth and promotes apoptosis of glioblastoma cells in vitro and in vivo. Tumour Biol 36: 4271-4278, 2015.

17. Liu YS, Luo XY, Li QR, Li H, Li C, Ni H, Li RX, Wang R, $\mathrm{Hu} \mathrm{HC}$, Pan YJ, et al: Shotgun and targeted proteomics reveal that pre-surgery serum levels of LRG1, SAA and C4BP may refine prognosis of resected squamous cell lung cancer. J Mol Cell Biol 4: 344-347, 2012.

18. Wen SY, Zhang LN, Yang XM, Zhang YL, Ma L, Ge QL, Jiang SH, Zhu XL, Xu W, Ding WJ, et al: LRG1 is an independent prognostic factor for endometrial carcinoma. Tumour Biol 35: 7125-7133, 2014

19. Kentsis A, Ahmed S, Kurek K, Brennan E, Bradwin G, Steen $\mathrm{H}$ and Bachur R: Detection and diagnostic value of urine leucine-rich $\alpha$-2-glycoprotein in children with suspected acute appendicitis. Ann Emerg Med 60: 78-83.e1, 2012.

20. Shirai R, Hirano F, Ohkura N, Ikeda K and Inoue S: Up-regulation of the expression of leucine-rich alpha(2)-glycoprotein in hepatocytes by the mediators of acute-phase response. Biochem Biophys Res Commun 382: 776-779, 2009.

21. Song $\mathrm{W}$ and Wang X: The role of TGF $\beta 1$ and LRG1 in cardiac remodeling and heart failure. Biophys Rev 7: 91-104, 2015.

22. Watson CJ, Ledwidge MT, Phelan D, Collier P, Byrne JC, Dunn MJ, McDonald KM and Baugh JA: Proteomic analysis of coronary sinus serum reveals leucine-rich $\alpha 2$-glycoprotein as a novel biomarker of ventricular dysfunction and heart failure Circ Heart Fail 4: 188-197, 2011.

23. Pek SL, Tavintharan S, Wang X, Lim SC, Woon K, Yeoh LY, $\mathrm{Ng} \mathrm{X}$, Liu J and Sum CF: Elevation of a novel angiogenic factor, leucine-rich- $\alpha 2$-glycoprotein (LRG1), is associated with arterial stiffness, endothelial dysfunction, and peripheral arterial disease in patients with type 2 diabetes. J Clin Endocrinol Metab 100 $1586-1593,2015$

24. Nakajima M, Miyajima M, Ogino I, Watanabe M, Miyata $H$, Karagiozov KL, Arai H, Hagiwara Y, Segawa T, Kobayashi K and Hashimoto Y: Leucine-rich $\alpha$-2-glycoprotein is a marker for idiopathic normal pressure hydrocephalus. Acta Neurochir (Wien) 153: 1339-1346; discussion 1346, 2011

25. Miyajima M, Nakajima M, Motoi Y, Moriya M, Sugano $H$, Ogino I, Nakamura E, Tada N, Kunichika M and Arai H: Leucine-rich $\alpha 2$-glycoprotein is a novel biomarker of neurodegenerative disease in human cerebrospinal fluid and causes neurodegeneration in mouse cerebral cortex. PLoS One 8 : e74453, 2013 .
26. Wang X, Abraham S, McKenzie JA, Jeffs N, Swire M, Tripathi VB, Luhmann UF, Lange CA, Zhai Z, Arthur HM, et al: LRG1 promotes angiogenesis by modulating endothelial TGF- $\beta$ signaling. Nature 499: 306-311, 2013.

27. Saito K, Tanaka T, Kanda H, Ebisuno Y, Izawa D, Kawamoto S, Okubo K and Miyasaka M: Gene expression profiling of mucosal addressin cell adhesion molecule-1+high endothelial venule cells (HEV) and identification of a leucine-rich HEV glycoprotein as a HEV marker. J Immunol 168: 1050-1059, 2002.

28. Zan L, Wu H, Jiang J, Zhao S, Song Y, Teng G, Li H, Jia Y, Zhou M, Zhang X, et al: Temporal profile of Src, SSeCKS, and angiogenic factors after focal cerebral ischemia: Correlations with angiogenesis and cerebral edema. Neurochem Int 58: 872-879, 2011.

29. Livak KJ and Schmittgen TD: Analysis of relative gene expression data using real-time quantitative PCR and the 2(-Delta Delta C(T)) Method. Methods 25: 402-408, 2001.

30. Yu Q, Zhao Z, Sun J, Guo W, Fu J, Burnstock G, He C and Xiang Z: Expression of P2X6 receptors in the enteric nervous system of the rat gastrointestinal tract. Histochem Cell Biol 133: 177-188, 2010.

31. Weidner N, Folkman J, Pozza F, Bevilacqua P, Allred EN, Moore DH, Meli S and Gasparini G: Tumor angiogenesis: A new significant and independent prognostic indicator in early-stage breast carcinoma. J Natl Cancer Inst 84: 1875-1887, 1992.

32. Mozaffarian D, Benjamin EJ, Go AS, Arnett DK, Blaha MJ, Cushman M, de Ferranti S, Després JP, Fullerton HJ, Howard VJ, et al: Heart disease and stroke statistics-2015 update: A report from the American heart association. Circulation 131: e29-e322, 2015.

33. Yoo SY and Kwon SM: Angiogenesis and its therapeutic opportunities. Mediators Inflamm 2013: 127170, 2013.

34. Manoonkitiwongsa PS: Critical questions for preclinical trials on safety and efficacy of vascular endothelial growth factor-based therapeutic angiogenesis for ischemic stroke. CNS Neurol Disord Drug Targets 10: 215-234, 2011.

35. Nakajima M, Miyajima M, Ogino I, Watanabe M, Hagiwara Y, Segawa T, Kobayashi K and Arai H: Brain localization of leucine-rich $\alpha 2$-glycoprotein and its role. Acta Neurochir Suppl 113: 97-101,2012.

36. Takemoto N, Serada S, Fujimoto M, Honda H, Ohkawara T, Takahashi T, Nomura S, Inohara H and Naka T: Leucine-rich $\alpha$-2-glycoprotein promotes TGF $\beta 1$-mediated growth suppression in the Lewis lung carcinoma cell lines. Oncotarget 6: 11009-11022, 2015.

37. Li Y, Zhang Y, Qiu F and Qiu Z: Proteomic identification of exosomal LRG1: A potential urinary biomarker for detecting NSCLC. Electrophoresis 32: 1976-1983, 2011.

38. Oh SP, Seki T, Goss KA, Imamura T, Yi Y, Donahoe PK, Li L, Miyazono K, ten Dijke P, Kim S and Li E: Activin receptor-like kinase 1 modulates transforming growth factor-beta 1 signaling in the regulation of angiogenesis. Proc Natl Acad Sci USA 97: 2626-2631, 2000

39. Orlova VV, Liu Z, Goumans MJ and ten Dijke P: Controlling angiogenesis by two unique TGF- $\beta$ type I receptor signaling pathways. Histol Histopathol 26: 1219-1230, 2011.

40. Ueki Y and Reh TA: Activation of BMP-Smad1/5/8 signaling promotes survival of retinal ganglion cells after damage in vivo. PLoS One 7: e38690, 2012

41. Poittevin M, Bonnin P, Pimpie C, Rivière L, Sebrié C, Dohan A, Pocard M, Charriaut-Marlangue C and Kubis N: Diabetic microangiopathy: Impact of impaired cerebral vasoreactivity and delayed angiogenesis after permanent middle cerebral artery occlusion on stroke damage and cerebral repair in mice. Diabetes 64: 999-1010, 2015. 